\title{
Reproductive biology of the seahorse Hippocampus fuscus (teleostei: syngnathidae), in the Suez Canal, Egypt.
}

\author{
Ashraf I. Ahmed; Howaida R. Gabr and Ola S. Khawasek \\ Marine Science Department, Faculty of Science, Suez Canal University, Ismailia, Egypt. \\ E-mail: ashrafibrahim2002@yahoo.com.
}

\section{ABSTRACT}

The reproductive biology of the drab seahorse, Hippocampus fuscus was investigated at two sites (Great Bitter Lakes and Lake Timsah) in the Suez Canal, Egypt, to determine sex ratio, reproductive maturity stages, gonad index, spawning season, and male/female fecundity. A total of 393 seahorses were collected from Great Bitter Lakes and 319 from Lake Timsah from August 2006 to July 2007. Male to female ratios did not depart significantly from a 1:1 ratio, either through the whole study period or between the seasons. Female seahorses progressed through three ovarian maturity stages during the reproductive cycle: Previtellogenic ovaries, Vitellogenic ovaries, and Mature ovaries. Hippocampus fuscus appears to undergo year-round reproduction in the Suez Canal, as reproductively mature females and brooding males with eggs/embryos in the brood pouch were captured every month of the year, although most mature specimens were collected in mid winter-early summer. The peak of female gonadosomatic index (GSI) coincided with the peak occurrence of mature ovaries in female seahorses. Vitellogenesis in female seahorses appears to be asynchronous. Female $H$. fuscus were relatively more fecund in Lake Timsah than in Great Bitter Lake; where fecundity ranged from 160 to 686 ova in Lake Timsah and from 86 to 372 ova in Great Bitter Lake. At both sites, female fecundity was positively correlated with seahorse height, total weight, and gonad weight. Male $H$. fuscus was also relatively more fecund (number of eggs and/or embryos in the brood pouch). Male fecundity was positively correlated to seahorse height. Female $H$. fuscus appeared to have higher fecundity than males in the sampled populations (i.e., mean number of ripe ova or clutch size exceeds the mean brood number). This study is so far the first to document aspects of the reproductive biology of $H$. fuscus in the Suez Canal and adds to our knowledge of this relatively poorly studied seahorse species.

Keywords: Hippocampus fuscus, Reproductive biology, Suez Canal ,Egypt

\section{INTRODUCTION}

Generally, seahorses are regarded as being directly threatened by human exploitation for medicinal, live aquarium and curio trades, as well as indirect fishing pressure through non-selective fishing gear or other disruptions such as habitat loss/degradation and environmental pollution around their coastal habitats (Vincent, 1996; Baum and Vincent, 2005). As a reflection of this, the entire seahorse genus Hippocampus is currently listed in Appendix II of the Convention on International Trade in Endangered Species (CITES).

Seahorses are known to possess "vulnerable" life history characteristics, such as: sparse distribution, lengthy parental care of young in marsupio by males, low mobility, small home ranges, and relatively low fecundity of female seahorses compared to many other fish species (Lourie et al., 1999; Bell et al., 2003; Foster and Vincent, 2004; Baum and Vincent, 2005; Martin-Smith and Vincent, 2005, 2006). In most cases, 
seahorses also exhibit mate fidelity so removal of a mate may impede finding a new mate. These life history characteristics and their implications for conservation and management were reviewed by Foster and Vincent (2004). However, differences in life history characteristics between seahorse species are likely to affect their relative vulnerability. Studies on the reproductive biology of seahorses provide essential information for understanding their reproductive patterns and strategies, and, hence vulnerability to abiotic and biotic impacts.

The drab seahorse, Hippocampus fuscus Rüppell 1838 is distributed from the eastern Mediterranean, through the Suez Canal, across to India and Sri Lanka, and down the east African coast to Madagascar (Lourie et al., 2004). Typically this species is reported from shallow waters $(<10 \mathrm{~m}$ depth) from artificial structures, stones, gravel, harbours and bays with calm water (Golani and Fine, 2002), and from shallow waters on the edges of algal reefs or seagrass beds (Kuiter, 2003). It is the only seahorse found in the Suez Canal and is known as a recent "Lessepsian migrant" via this route into the Mediterranean (Golani and Fine, 2002). Growing to a maximum height of $14 \mathrm{~cm}$, this species is exploited for medicinal, live aquarium and curio trades (Lourie et al., 2004; Salin et al., 2005). In Egypt, there is no targeted fishery for $H$. fuscus, but they are harvested as a fisheries bycatch. Hippocampus fuscus is currently listed as Data Deficient by The World Conservation Union (Project Seahorse, 2003). Little is known about this species, particularly with regards to reproduction, other than from small-scale laboratory studies (Vincent, 1990; Golani and Fine, 2002).

This study investigates sex ratio, maturity stages, gonad index, reproductive season, and male/female fecundity of $H$. fuscus in the Suez Canal. This research presents the first detailed study dealing with the reproductive biology of $H$. fuscus in the wild.

\section{MATERIALS AND METHODS}

\section{Sampling sites and seahorse collection}

Seahorses were collected from two Suez Canal sites: site 1, Shaffiee beach in Great Bitter Lake, and site 2, Mallaha beach in Lake Timsah. The Bitter Lakes and Lake Timsah constitute the main water bodies in Suez Canal area (Fig. 1). Sampling was carried out monthly from August 2006 till July 2007. Seahorses were collected by hand during snorkeling at depths ranging between 50 and $150 \mathrm{~cm}$, with water clarity ranging from $100 \mathrm{~cm}$ (Great Bitter Lake) to $40 \mathrm{~cm}$ (Lake Timsah). Site 1 seahorses were found attached to fouling substratum (the macroalgae; Ulva sp., Enteromorpha sp., and to a lesser amount Jania sp.) nearby an old jetty. Site 2 seahorses were found amongst seagrass beds; Halophila stipulacea and Halodule uninervis extending along the beach. At both sites all seahorses encountered during each sampling event were collected.

Salinity and water temperature were recorded monthly during the whole period of the study by using a refractometer and digital thermometer respectively.

\section{Seahorses processing}

Immediately after collection, seahorses were relaxed with chloroform $(2.5 \mathrm{ml}$ chloroform $/ 100 \mathrm{ml}$ seawater) and then preserved in $10 \%$ formalin. A sub-sample of 3-5 animals (representing the full size range) was taken from each monthly sample for histology. Small central sections were dissected from the ovary, fixed for 24 hours in Bouin's solution, and then transferred to $70 \%$ ethyl alcohol for preservation. Clearing and paraffin embedding were performed using standard histological techniques; sections were cut at $6 \mu \mathrm{m}$ thicknesses and stained with hematoxylin and eosin. Oocytes were staged according to Wallace and Selman (1981); Begovac and Wallace (1987, 1988); Selman et al. (1991) and Poortenaar et al. (2004). Ovaries were classified by their 
developmental stage according to the most advanced stage of oocytes present in the section.

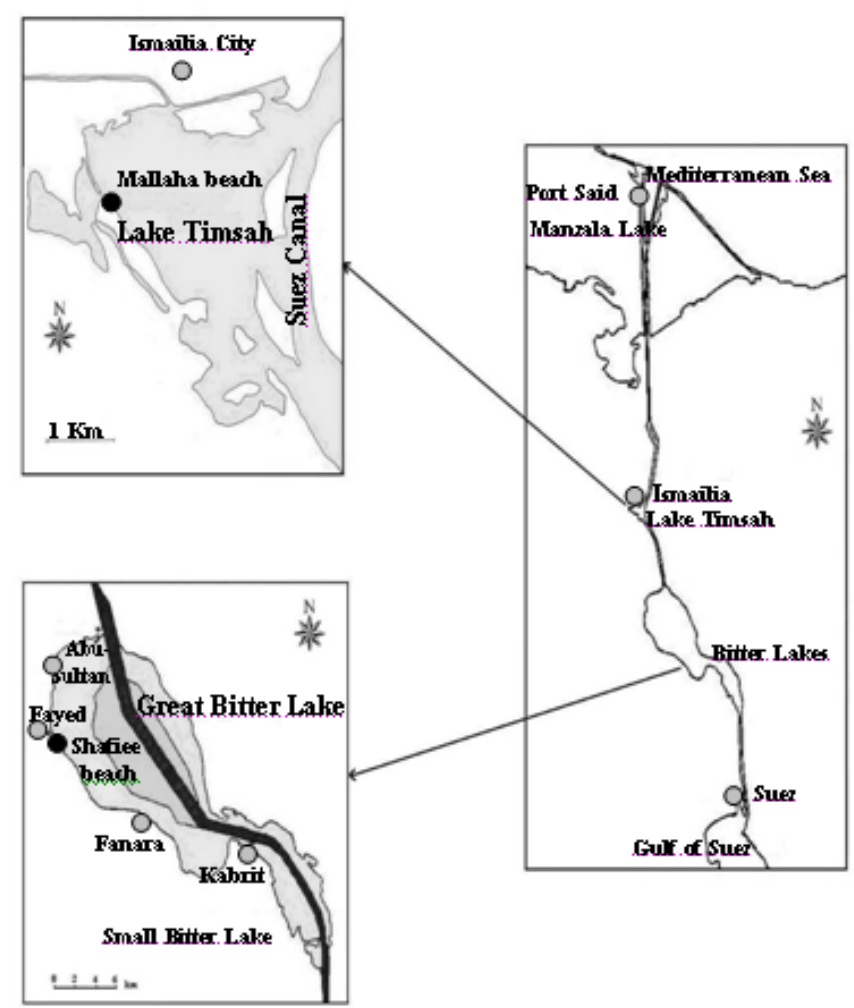

Fig.1: Map showing the locations of the sampling sites: Mallaha beach in Lake Timsah, and Shafiee beach in Great Bitter Lake, Suez Canal, Egypt.

Large-sized seahorses were sexed by morphological examination (i.e., presence or absence of brood pouch (Foster and Vincent, 2004)), whilst small-sized seahorses were sexed after dissection. The total body wet weight to the nearest $0.1 \mathrm{~g}$, and height (the vertical distance from the tip of the coronet to the tip of the extended tail) to the nearest $1 \mathrm{~mm}$ were measured with vernier calipers and recorded for each seahorse collected.

\section{Female seahorse gonado-somatic index}

Preserved seahorses were dissected, and macroscopic examination of the gonads was carried out. Due to the consistently very small size of male seahorse testes, estimation of gonado-somatic index (GSI) was only carried out for females. The gonads of females were separated and weighed to the nearest $0.1 \mathrm{gm}$, and then preserved in $70 \%$ ethyl alcohol for detailed study. GSI was then calculated for each female by the following equation: GSI $=$ Ovary wet weight $\times 100 /$ Total body wet weight

\section{Female fecundity and oocyte diameter}

Fecundity was determined in 79 mature females (ovary maturity stage III), 42 collected from Lake Timsah and 37 collected from Great Bitter Lake. Fecundity was estimated as the total number of all different stages of oocytes in the ovary. Meanwhile, immediate fecundity (clutch size) was determined by counting the total number of mature (ripe) ova in the ovary. Ova were not always perfectly symmetrical, therefore both longest and shortest ova diameters were measured and an average diameter calculated from these two measures. Ova counting and measurement were carried out with a binocular dissecting microscope equipped with an ocular micrometer.

Ova were grouped depending on their color and developmental stage into: small transparent oocytes \{Chromatin nucleolus oocytes (CN), Perinucleolar oocytes (PN), Cortical alveoli oocytes $(\mathrm{CA})\}$ which represent immature oocytes, and large, orange 
oocytes $\{$ Vitellogenic oocytes (V), and Mature oocytes (M)\} which represent ripe or mature oocytes.

\section{Estimation of male seahorse fecundity}

The brood pouch of brooding (pregnant) male seahorses was dissected open and the contents (deposited eggs and/or developing embryos) counted to estimate male fecundity.

\section{RESULT}

\section{Temperature and salinity}

The mean monthly seawater temperature and salinity at the sampling sites listed in Table 1. Temperature did not significantly differ between the two sites, with an average of $22.1 \pm 5.1^{\circ} \mathrm{C}$ (range $16.0-29.8^{\circ} \mathrm{C}$ ) and $22.7 \pm 5.3^{\circ} \mathrm{C}$ (range $17.2-30.2^{\circ} \mathrm{C}$ ) in Great Bitter Lake and Lake Timsah respectively ( $t$-test, $t=0.28 ; \mathrm{P}>0.05$ ). Great Bitter Lake was consistently of higher salinity than Lake Timsah, with average salinities $39.6 \pm 1.2$ (range 37.0-42.0\%o) and 28.8 $\pm 3.9 \%$ (range 24.3-36.2\%o) in Great Bitter Lake and Lake Timsah respectively ( $t$-test, $t=9.17 ; \mathrm{P}<0.001)$.

Table 1. Monthly mean \pm SD values of seawater temperature and salinity in Great Bitter Lake and Lake Timsah, Suez Canal.

\begin{tabular}{ccccc}
\hline Month & $\begin{array}{c}\text { Water temperature }\left({ }^{\circ} \mathbf{C}\right) \\
\text { Great Bitter } \\
\text { Lake }\end{array}$ & Lake Timsah & $\begin{array}{c}\text { Salinity (\%o) } \\
\text { Great Bitter } \\
\text { Lake }\end{array}$ & Lake Timsah \\
\hline Aug-02 & 29.8 & 30.2 & 42.0 & 32.0 \\
Sep. & 28.5 & 29.3 & 41.0 & 26.1 \\
Oct. & 25.0 & 26.2 & 40.0 & 25.3 \\
Nov. & 20.2 & 21.6 & 39.2 & 29.8 \\
Dec. & 18.5 & 17.3 & 39.5 & 25.1 \\
Jan-03 & 16.0 & 17.2 & 37.0 & 24.3 \\
Feb. & 17.0 & 17.3 & 39.4 & 27.8 \\
Mar. & 16.5 & 17.5 & 39.7 & 36.2 \\
Apr. & 18.5 & 18.1 & 40.0 & 35.1 \\
May & 21.5 & 22.2 & 39.7 & 28.1 \\
Jun. & 25.2 & 26.3 & 38.5 & 26.7 \\
Jul. & 28.9 & 29.6 & 39.0 & 29.1 \\
\hline Mean \pm SD & $22.1 \pm 5.1$ & $22.7 \pm 5.3$ & $39.6 \pm 1.2$ & $28.8 \pm 3.9$ \\
\hline
\end{tabular}

\section{Sex ratio}

In Great Bitter Lake, of a total 393 collected seahorses, 204 were male (51.91\%) and 189 were female (48.09\%). In Lake Timsah, of a total 319 collected seahorses, 152 were male $(47.65 \%)$ and 167 were female $(52.35 \%)$. Chi-square test was used to detect if there is a significant deviation from a 1:1 sex ratio. Male to female ratios did not depart significantly from the ratio $1: 1$, either throughout the whole study period $(\mathrm{Chi}=$ $0.72, \mathrm{P}>0.5)$ or between the seasons $(\mathrm{Chi}=0.68, \mathrm{P}>0.5)$.

\subsection{Ovarian maturity stages}

Three stages of ovarian maturity for female Hippocampus fuscus were recognized and are described below:

Stage I (Previtellogenic ovaries): Morphologically, previtellogenic ovaries are small, soft, thin, and creamy white in colour. Histologicaly, this stage contains the following oocytes (Fig. 2): 1- Chromatin - nucleus (CN), which is characterized by the presence of large sized nucleolus compared to cytoplasm, the nucleolus contains multiple nucleoli. 2- Perinucleolar oocytes $(\mathrm{PN})$, which are characterized by the presence of small sized nucleus compared to cytoplasm. The nucleus contains multiple nucleoli 
around the nucleus periphery. PN oocytes are usually round or oval, but sometimes appear elongated with irregular edges. 3- Cortical alveoli (CA), this oocyte is more elongated in shape and characterized by a membrane structure having a homogenous appearance.

Stage II (Vitellogenic ovaries): Morphologically, vitellogenic ovaries are granulated, and orange color starts to appear, although it does not dominate. Histologicaly, this stage contains all oocytes as found in previtellogenic ovary, beside the presence of vitellogenic oocytes (V), which increase in size and begin to elongate, and in which yolk vesicles appear and coalesce (Fig. 3).

Stage III (Mature ovaries): Morphologically, mature ovaries are much enlarged and bright orange in colour. Histologically, they contain all the oocytes stages found in the vitellogenic ovaries besides the presence of mature oocytes, which are pear shaped. Mature oocytes are characterized by the presence of central yolk mass and a peripheral rim of lipid sphere (Fig. 4).

Monthly variations in female maturity stages

The percentage monthly composition of female $H$. fuscus with regard to different maturity stages in Great Bitter Lake and Lake Timsah were illustrated in Figs. 5 and 6 respectively. The pattern of ovarian maturation was similar at both studied sites. There was a pronounced peak in the percentage of previtellogenic females (stage I) during August to December. Females with vitellogenic ovaries (stage II) occurred all year, although with variable percentages. The peak incidence of mature females (stage III) was seen mainly from January to June, although some mature females were always present in every sampled month.

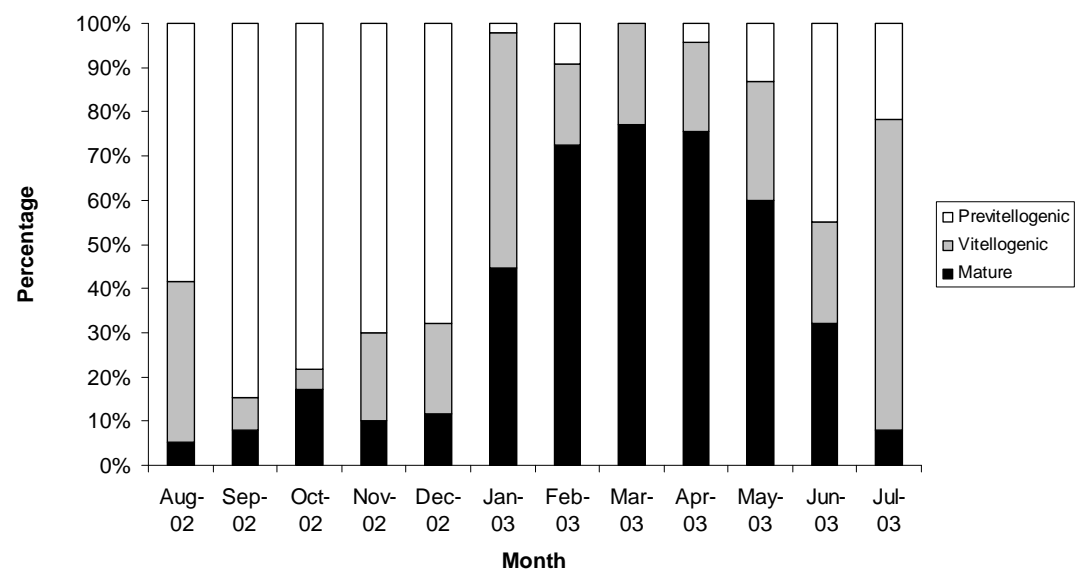

Fig. 5: Monthly variation in female Hippocampus fuscus ovarian maturity stages (I - III) in Great Bitter Lake. Maturity stages: (I) Previtellogenic, (II) Vitellogenic, and (III) Mature.

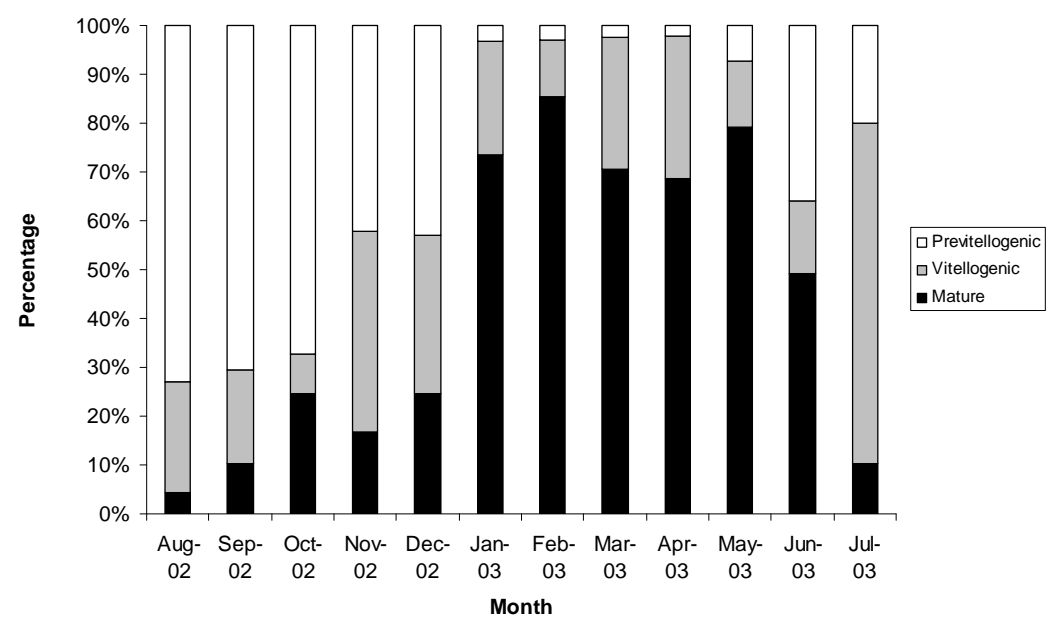


Fig. 6: Monthly variations in female Hippocampus fuscus at different maturity stages (I - III) in Lake Timsah.

\section{Monthly variations in male brooding}

Figs. 7 and 8 illustrate the monthly percentage composition of brooding and nonbrooding males in Great Bitter Lake and Lake Timsah respectively. Increasing percentage composition of brooding males corresponded with female reproductive patterns at both sites (Figs. 5 and 6). At both sites, the percentage of brooding males started to increase gradually from January upwards till June, with a maximum occurrence in April $(93.33 \%$ and $85.71 \%$ in Great Bitter Lake and Lake Timsah respectively). Meanwhile, the highest percentage of nonbrooding males was recorded from August to January.

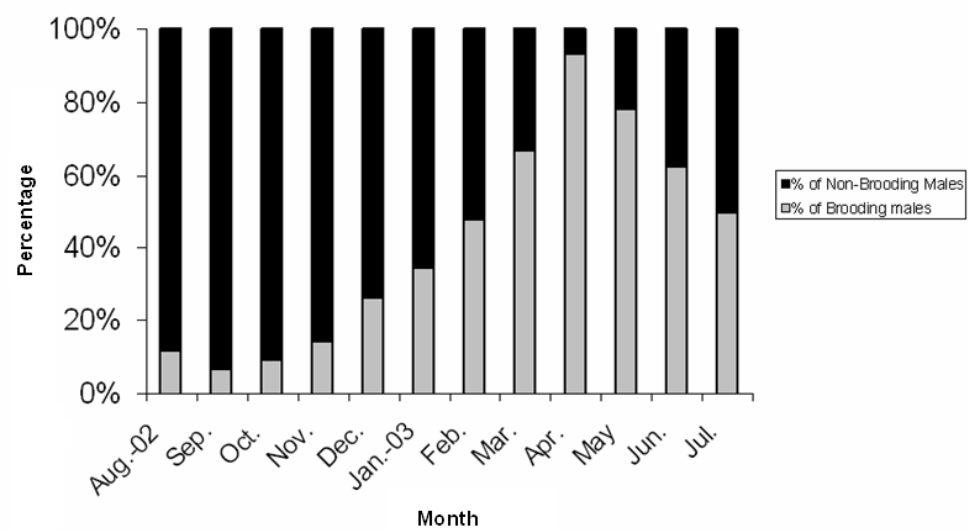

Fig.7: Monthly changes in percentage of brooding and non-brooding male Hippocampus fuscus collected from Great Bitter Lake.

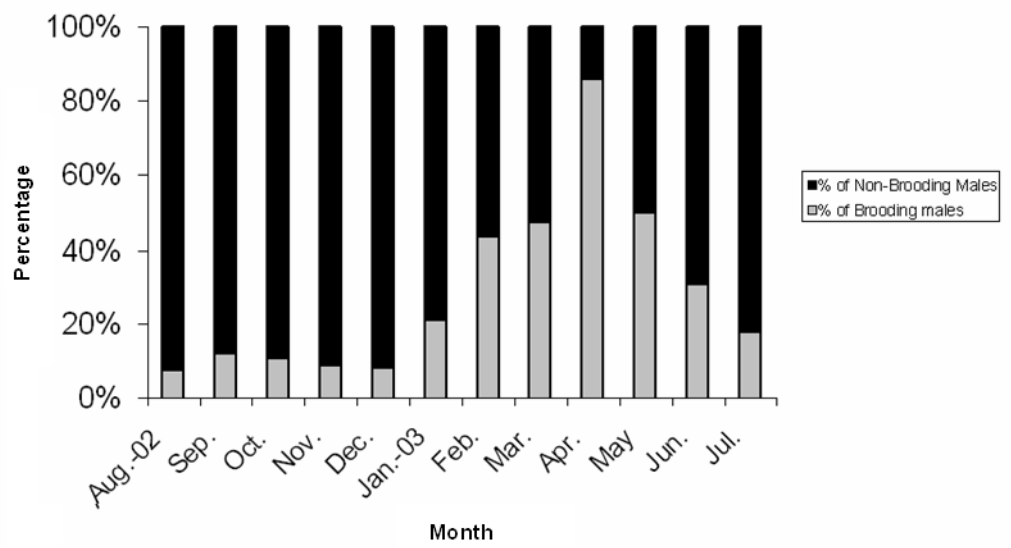

Fig.8: Monthiy cnanges in percentage or orooaing and non-orooaing maie rıppocampus fuscus collected from Lake Timsah.

\section{Monthly variations in female GSI}

The female seasonal reproductive pattern suggested by ovarian maturity stages is supported by gonado-somatic index data (GSI). Figs. 9 and 10 illustrate the mean gonad index of female $H$. fuscus in Great Bitter Lake and Lake Timsah respectively. Monthly variation in GSI was pronounced and shows the same pattern at both study sites. GSI increased gradually in January to reach its highest level in March-May, coinciding with the peak incidence of mature female ovarian stage (III) (Figs. 5 and 6). In Great Bitter Lake, the highest mean GSI recorded was $7.13 \% \pm 2.24$ in March and the lowest was $0.47 \% \pm 0.40$ in December. In Lake Timsah, the highest mean GSI recorded was $8.95 \% \pm 4.83$ in April and the lowest was $0.50 \% \pm 0.33$ in September.

\section{Female fecundity}

In Great Bitter Lake, the total number of ova in mature (ovarian stage III) female $H$. fuscus varied from 86 in a female of $7.5 \mathrm{~cm}$ height of $1.49 \mathrm{~g}$ total weight and an ovary weight of $0.07 \mathrm{~g}$, to 372 in a female of $9.4 \mathrm{~cm}$ height, $2.97 \mathrm{~g}$ total weight and an ovary weight of $0.37 \mathrm{~g}$ (Table 2). In Lake Timsah, the total number of ova ranged from 160 in a female of $11.9 \mathrm{~cm}$ 
height, $5.05 \mathrm{~g}$ total weight and an ovary weight of $0.12 \mathrm{~g}$, to 686 in a female of $11.2 \mathrm{~cm}$ height, $5.59 \mathrm{~g}$ total weight and an ovary weight of $0.75 \mathrm{~g}$ (Table 2 ).

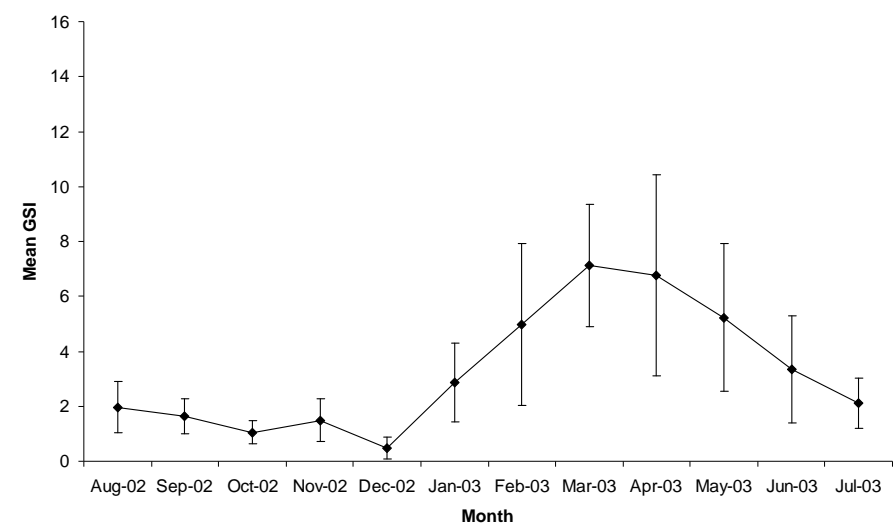

Fig. 9: Variation in monthly mean \pm SD gonado-somatic index (GSI) of female Hippocampus fuscus collected from Great Bitter Lake.

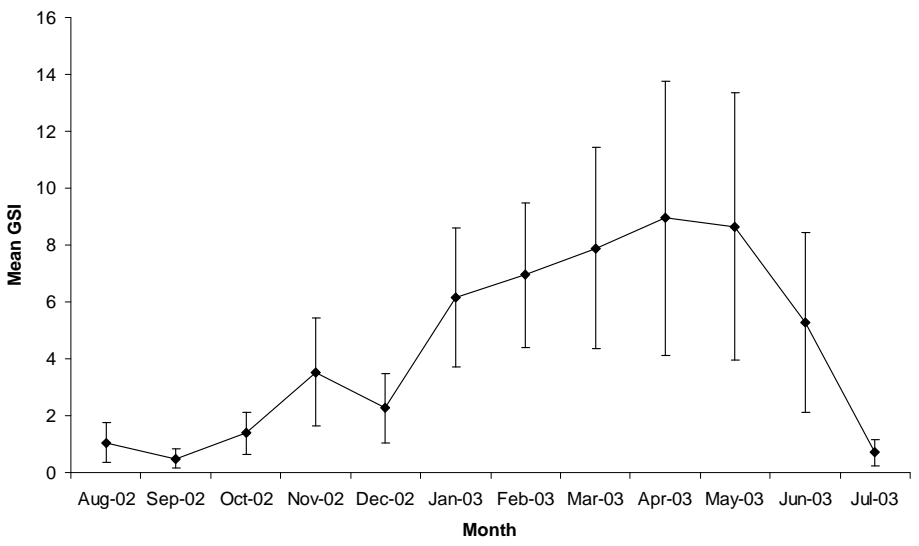

Fig.10: Monthly variations in mean \pm SD gonado-somatic index (GSI) of female Hippocampus fuscus collected from Lake Timsah.

Table 2: Mean fecundity (all different stages of ova) with height, total weight, and ovary weight of female Hippocampus fuscus collected from Great Bitter Lake and Lake Timsah, Suez Canal. $\mathrm{N}=$ number of animals in each size class; $\mathrm{M} \pm \mathrm{SD}=$ mean \pm standard deviation.

\begin{tabular}{|c|c|c|c|c|c|c|c|c|c|c|}
\hline \multicolumn{2}{|c|}{ Great Bitter Lake } & & & & & & & & & \\
\hline \multirow{2}{*}{ Height (cm) } & \multirow{2}{*}{$\mathbf{N}$} & \multicolumn{3}{|c|}{ Total weight (g) } & \multicolumn{3}{|c|}{ Ovary weight (g) } & \multicolumn{3}{|c|}{ Fecundity } \\
\hline & & Min. & Max. & $\mathbf{M} \pm \mathbf{S D}$ & Min. & Max. & $\mathbf{M} \pm \mathbf{S D}$ & Min. & Max. & $\mathbf{M} \pm \mathbf{S D}$ \\
\hline $6.9-7.8$ & 8 & 1.22 & 1.59 & $1.40 \pm 0.55$ & 0.03 & 0.11 & $0.07 \pm 0.03$ & 86 & 292 & $173.62 \pm 79.81$ \\
\hline $7.9-8.8$ & 15 & 1.48 & 8.60 & $2.86 \pm 1.43$ & 0.06 & 0.43 & $0.18 \pm 0.07$ & 120 & 321 & $199.93 \pm 80.65$ \\
\hline $8.9-9.8$ & 9 & 1.68 & 3.42 & $2.59 \pm 1.33$ & 0.10 & 0.37 & $0.24 \pm 0.09$ & 94 & 372 & $235.66 \pm 107.49$ \\
\hline $9.9-10.8$ & 5 & 2.63 & 3.73 & $3.25 \pm 1.72$ & 0.07 & 0.31 & $0.14 \pm 0.08$ & 98 & 313 & $194.60 \pm 99.33$ \\
\hline \multicolumn{11}{|c|}{ Lake Timsah } \\
\hline \multirow{2}{*}{ Height (cm) } & \multirow{2}{*}{$\mathbf{N}$} & \multicolumn{3}{|c|}{ Total weight (g) } & \multicolumn{3}{|c|}{ Ovary weight (g) } & \multicolumn{3}{|c|}{ Fecundity } \\
\hline & & Min. & Max. & $\mathbf{M} \pm \mathbf{S D}$ & Min. & Max. & $\mathbf{M} \pm \mathbf{S D}$ & Min. & Max. & $\mathbf{M} \pm \mathbf{S D}$ \\
\hline $7.9-8.8$ & 2 & 2.78 & 2.86 & $2.82 \pm 1.49$ & 0.25 & 0.44 & $0.35 \pm 0.14$ & 276 & 459 & $367.50 \pm 88.75$ \\
\hline $8.9-9.8$ & 5 & 3.03 & 4.00 & $3.38 \pm 1.8$ & 0.13 & 0.50 & $0.33 \pm 0.19$ & 245 & 366 & $326.40 \pm 154.32$ \\
\hline $9.9-10.8$ & 16 & 3.15 & 5.51 & $4.15 \pm 2.42$ & 0.10 & 0.77 & $0.39 \pm 0.20$ & 194 & 636 & $375.56 \pm 178.00$ \\
\hline $10.9-11.8$ & 12 & 4.08 & 6.79 & $5.46 \pm 2.68$ & 0.11 & 0.75 & $0.36 \pm 0.17$ & 175 & 686 & $427.08 \pm 284.54$ \\
\hline $11.9-12.8$ & 5 & 3.71 & 6.81 & $5.54 \pm 2.97$ & 0.12 & 0.63 & $0.32 \pm 0.19$ & 160 & 403 & $289.80 \pm 159.90$ \\
\hline $12.9-13.8$ & 2 & 7.33 & 7.42 & $7.38 \pm 3.77$ & 0.47 & 0.51 & $0.49 \pm 0.19$ & 252 & 594 & $423.00 \pm 223.50$ \\
\hline
\end{tabular}


The relationship between seahorse height and fecundity (total number of ova) of female $H$. fuscus was described by the equations $\mathrm{y}=39.44 \mathrm{x}+163.8$ in Great Bitter Lake and $y=18.76 x+148.2$ in Lake Timsah. At both sites, fecundity showed a positive correlation with height, but the relationships were weak $\left(\mathrm{r}^{2}=0.36, \mathrm{P}<0.05\right.$ and $\mathrm{r}^{2}=$ $0.22, \mathrm{P}<0.05$ in Great Bitter Lake and Lake Timsah respectively). The relationship between total weight and fecundity is described by the equations $\mathrm{y}=41.71 \mathrm{x}+144.8$ in the Bitter Lake and $y=22.44 x+274.9$ in Lake Timsah. At both sites, there was also a positive correlation between total weight and fecundity, although the relationships were weak $\left(\mathrm{r}^{2}=0.37, \mathrm{P}<0.05\right.$ and $\mathrm{r}^{2}=0.30, \mathrm{P}<0.05$ in Great Bitter Lake and Lake Timsah respectively). A similar relationship was also found between ovary weight and fecundity, described by the equations $y=338.30 x+168.3$ in Great Bitter Lake and $y=$ $242.50 x+278.5$ in Lake Timsah, although the relationships were relatively weak $\left(\mathrm{r}^{2}=\right.$ $0.57, \mathrm{P}<0.05$ and $\mathrm{r}^{2}=0.43, \mathrm{P}<0.05$ in Great Bitter Lake and Lake Timsah respectively).

\section{Monthly variation in ova diameter}

The monthly frequency distribution of ova diameter in female $H$. fuscus from Great Bitter Lake and Lake Timsah is illustrated in (Figs. 11 and 12) respectively. At both sites there were ova of a wide variety of sizes, indicating the potential of continual ova production. The frequency distribution of immature ova showed a similar pattern in all seahorses examined at both sites. The size range of immature ova ranged from 0.05 to $0.84 \mathrm{~mm}$ diameter, with an obvious increase in percentages of ova from $0.25 \mathrm{~mm}$ to $0.64 \mathrm{~mm}$ diameter. In Great Bitter Lake, there was always a wide size range of maturing and mature ova $(0.85 \mathrm{~mm}$ to $2.44 \mathrm{~mm}$ diameter with average ova diameter $1.7 \pm 0.49)$, while in Lake Timsah, maturing and mature ova had a wider size range ( 0.85 to 2.84 $\mathrm{mm}$ diameter with average ova diameter $1.9 \pm 0.38 \mathrm{~mm}$ ). At both sites, the percentage and the size range of maturing and mature ova increased from December to June when most of specimens were in mature stage (III); whilst the percentage and the size range of these ova started to decrease in July.

\section{Fecundity (output) of male seahorses}

In Great Bitter Lake, the number of eggs and/or embryos in brooding mature male $H$. fuscus ranged from 18 in a male of $7.5 \mathrm{~cm}$ height to 93 in a male of $12 \mathrm{~cm}$ height. In Lake Timsah, male fecundity was relatively high, varying from 24 in a male of $9.5 \mathrm{~cm}$ height to 168 in a male of $13.5 \mathrm{~cm}$ height. The relationship between fecundity and height of male $H$. fuscus is described by the equations $y=12.56 \mathrm{x}-73.34$ in Great Bitter Lake and $y=14.32 x-112.18$ in Lake Timsah. Although the number of eggs and/or embryos tended to increase with male seahorse height in the two sites, the relationships were relatively weak $\left(\mathrm{r}^{2}=0.47, \mathrm{P}<0.05\right.$ and $\mathrm{r}^{2}=0.32, \mathrm{P}<0.05$ in Great Bitter Lake and Lake Timsah respectively).

Monthly changes in mean clutch size or immediate fecundity (number of ripe eggs in female ovary) and fecundity or brood size (number of eggs or embryos in male pouch) in Great Bitter Lake and Lake Timsah is shown in Table 3. At both sites, mean female clutch size was generally greater than mean male brood size. The maximum average clutch size $(95.33 \pm 2.08$ and $139.4 \pm 3.64$ in Great Bitter Lake and Lake Timsah respectively) and brood size $(70 \pm 1.05$ and $115 \pm 2.13$ in Great Bitter Lake and Lake Timsah respectively) were recorded in March, whilst the minimum average clutch size $(20.5 \pm 1.76$ and $36 \pm 2.4$ in Great Bitter Lake and Lake Timsah Respectively) and brood size (17 \pm 1.33 and $22 \pm 1.34$ in Great Bitter Lake and Lake Timsah respectively) were recorded in August. 


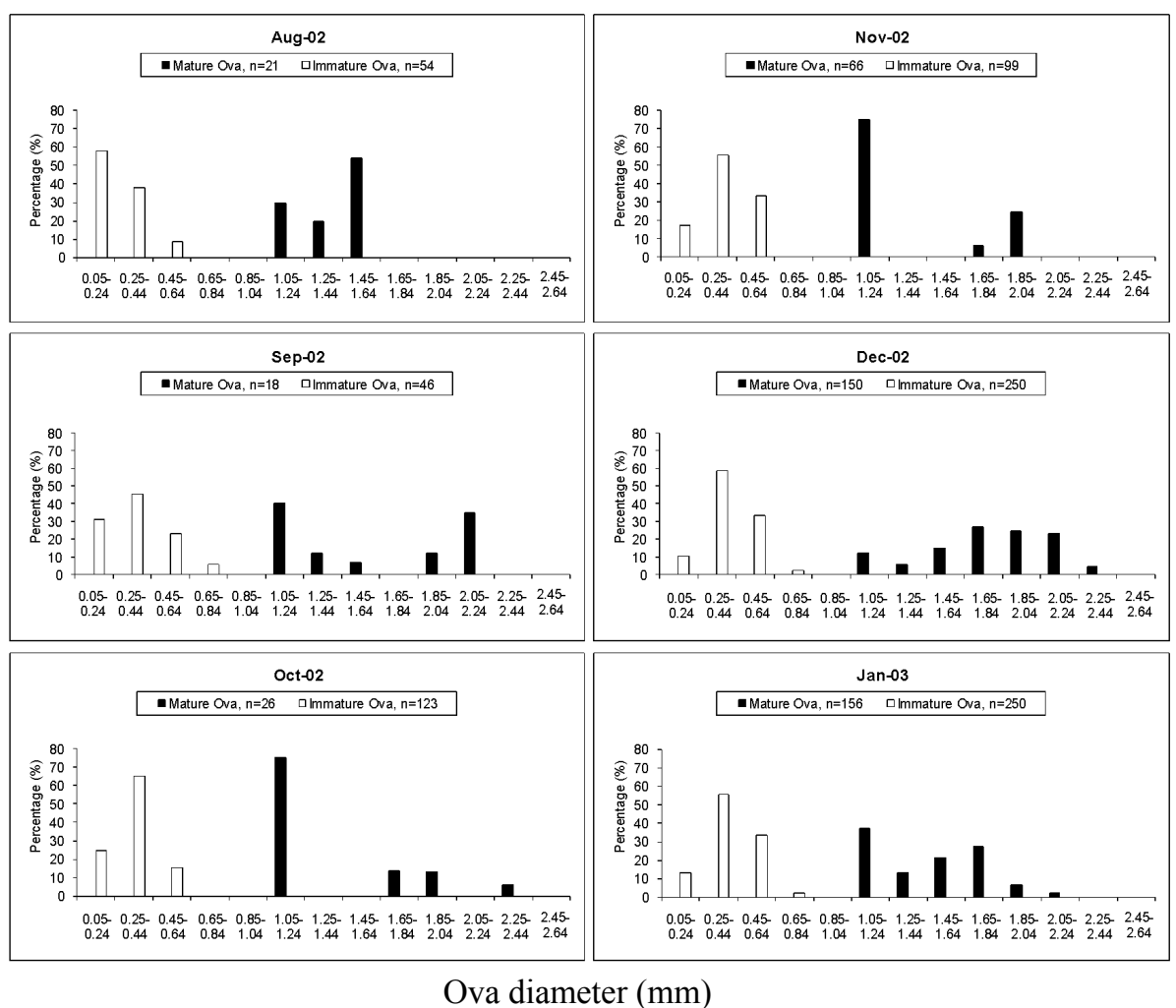

Fig.11: Monthly frequency distribution of ova diameter in the ovaries of female Hippocampus fuscus collected from Great Bitter Lake.
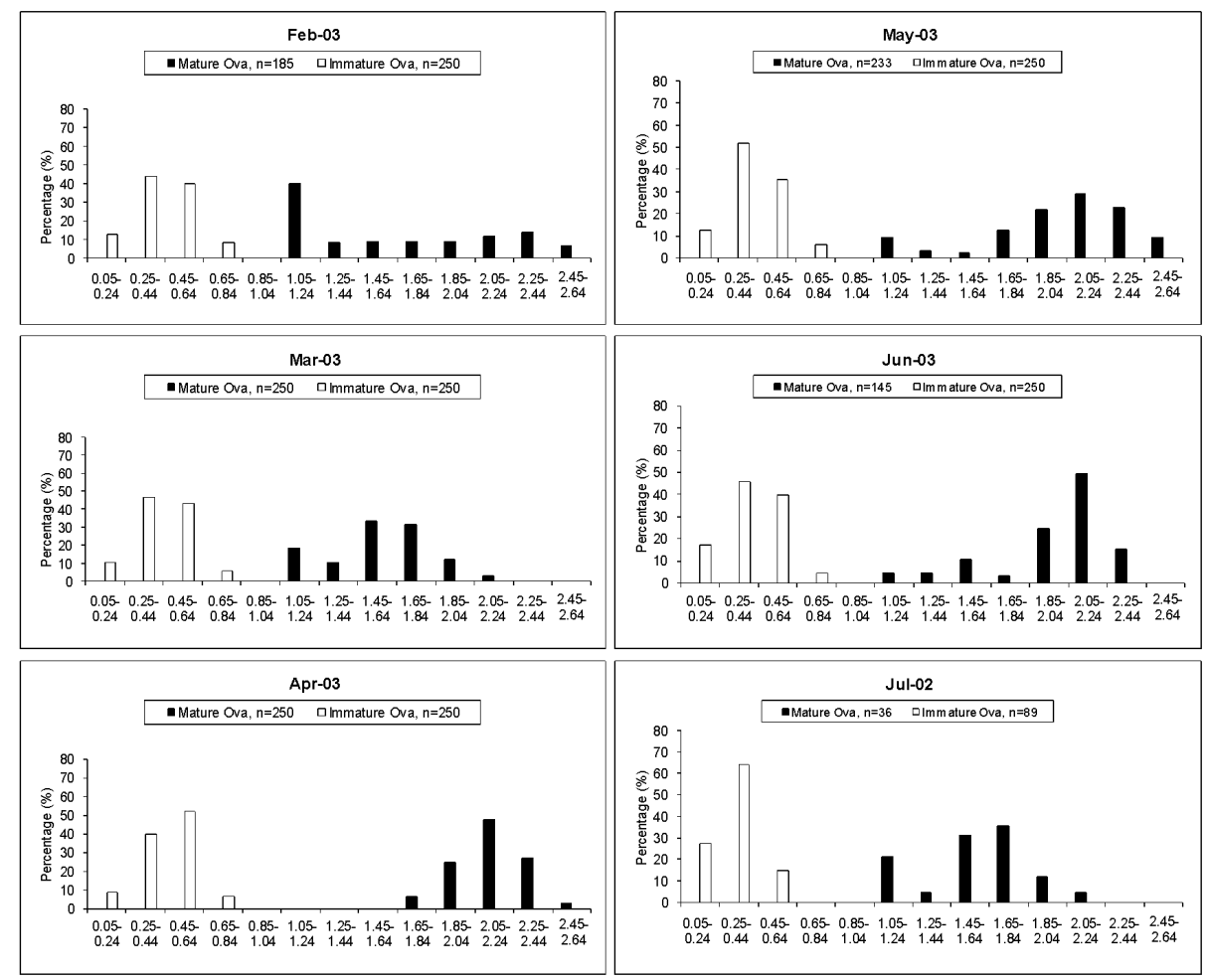

Ova diameter $(\mathrm{mm})$

Fig.11: (continued) Monthly frequency distribution of ova diameter in the ovaries of female Hippocampus fuscus collected from Great Bitter Lake. 

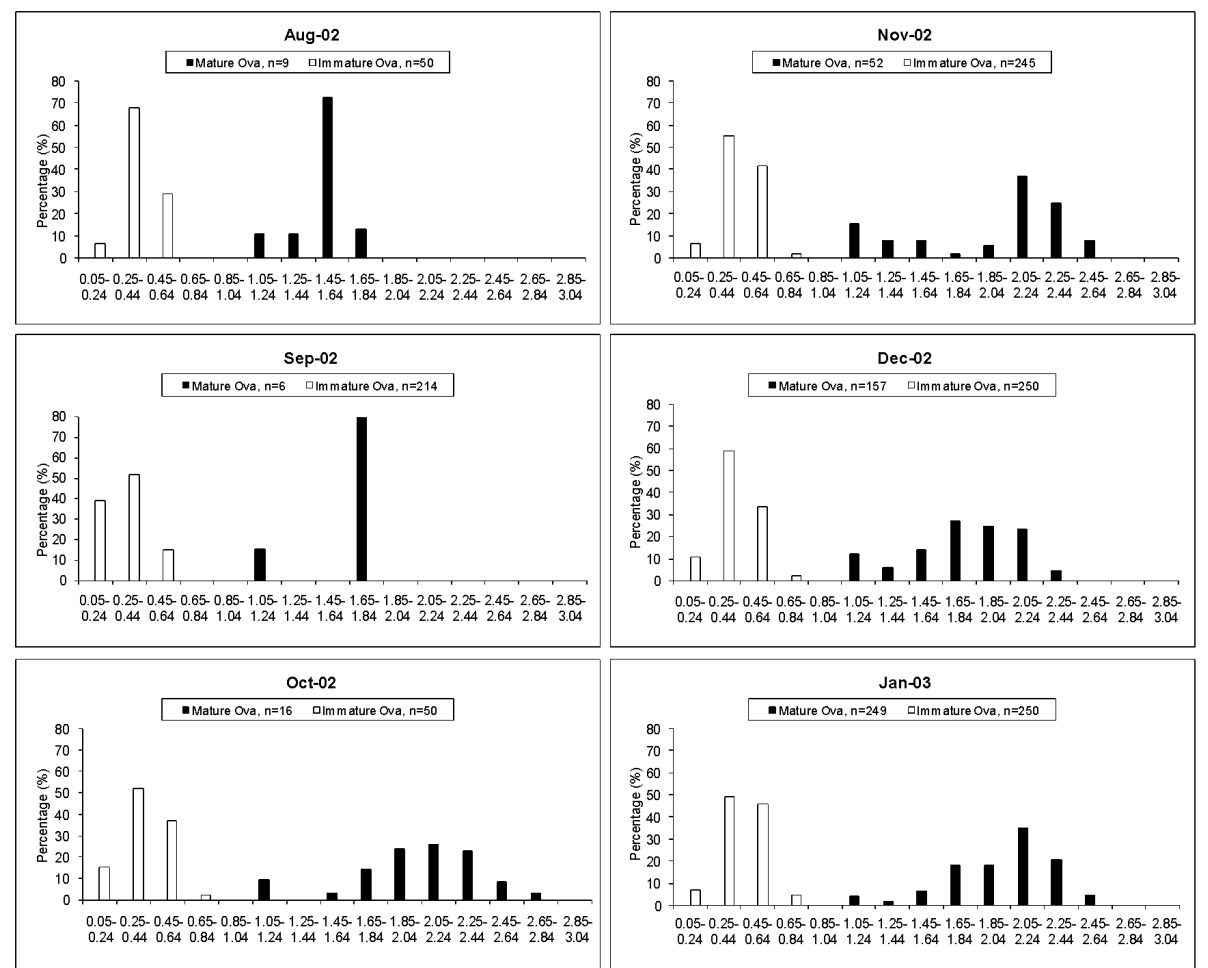

Ova diameter $(\mathrm{mm})$

Fig. 12: Monthly frequency distribution of ova diameter in the ovaries of female Hippocampus fuscus collected from Lake Timsah.
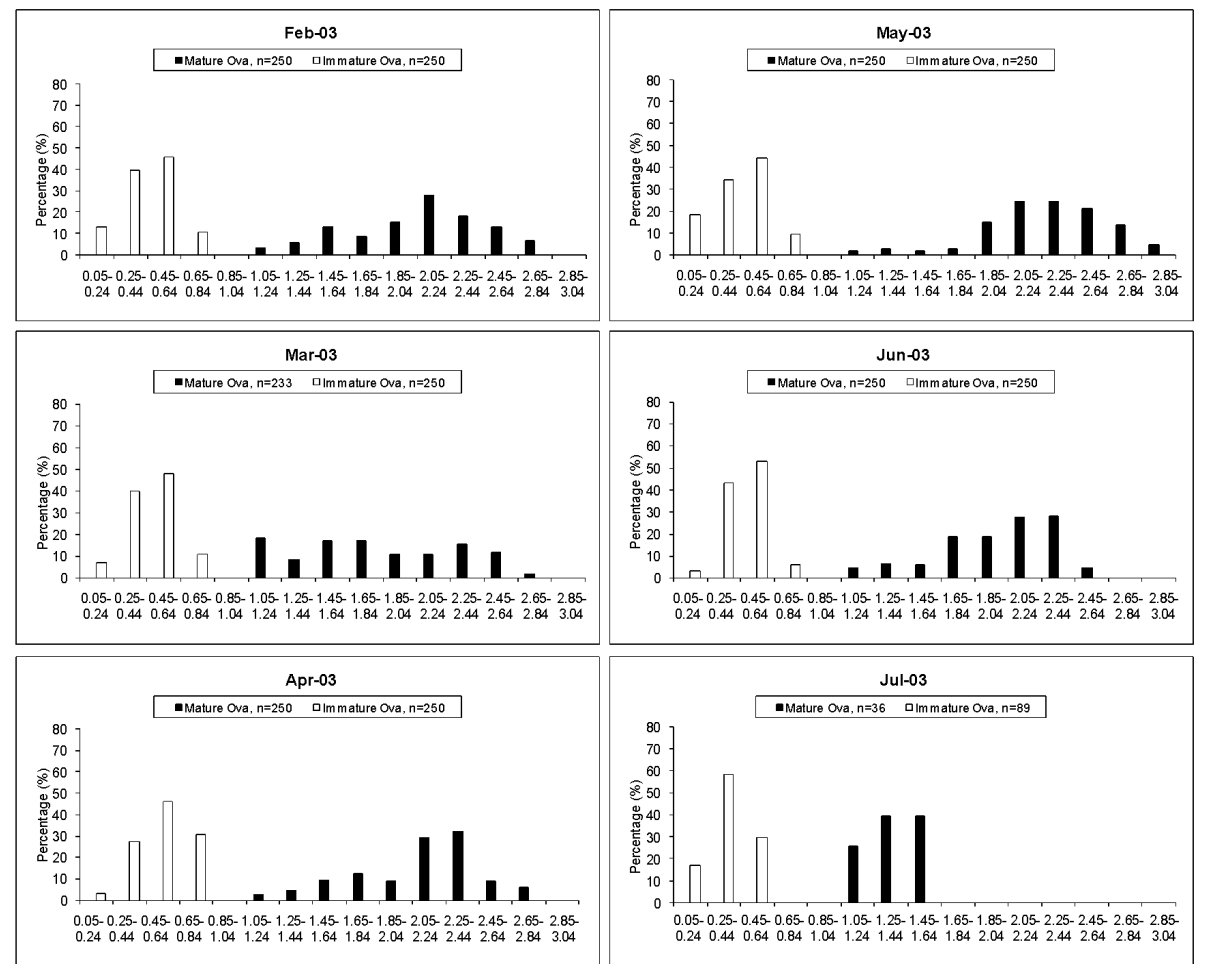

Ova diameter (mm)

Fig.12: (continued) Monthly frequency distribution of ova diameter in the ovaries of female Hippocampus fuscus collected from Lake Timsah. 
Table3. Monthly mean \pm SD immediate female fecundity (number of ripe ova in female ovary) and male fecundity (number of eggs and/or embryos within male pouch) of Hippocampus fuscus collected from Great Bitter Lake and Lake Timsah, Suez Canal.

\begin{tabular}{|c|cc|cc|}
\hline & \multicolumn{2}{|c|}{ Great Bitter Lake } & \multicolumn{2}{c|}{ Lake Timsah } \\
\hline Month & Female fecundity & Male fecundity & Female fecundity & Male fecundity \\
\hline Aug-02 & $20.50 \pm 1.76$ & $17.00 \pm 1.33$ & $36.00 \pm 2.40$ & $22.00 \pm 1.34$ \\
Sep & $22.00 \pm 1.37$ & $20.00 \pm 0.45$ & $38.00 \pm 3.20$ & $25.00 \pm 3.22$ \\
Oct & $25.00 \pm 2.43$ & $18.00 \pm 0.62$ & $40.00 \pm 2.30$ & $32.50 \pm 4.21$ \\
Nov. & $43.00 \pm 2.22$ & $26.75 \pm 1.94$ & $50.00 \pm 1.98$ & $35.00 \pm 2.65$ \\
Dec & $45.00 \pm 1.64$ & $20.00 \pm 1.28$ & $60.00 \pm 1.56$ & $48.00 \pm 1.78$ \\
Jan-03 & $32.20 \pm 1.88$ & $20.00 \pm 2.39$ & $95.40 \pm 2.35$ & $42.00 \pm 2.34$ \\
Feb. & $37.71 \pm 3.57$ & $30.00 \pm 2.39$ & $115.40 \pm 2.76$ & $50.00 \pm 1.57$ \\
Mar. & $95.33 \pm 2.08$ & $70.00 \pm 1.05$ & $139.40 \pm 3.64$ & $115.00 \pm 2.13$ \\
Apr. & $82.20 \pm 1.42$ & $66.73 \pm 2.23$ & $113.40 \pm 1.99$ & $77.70 \pm 2.22$ \\
Mary & $46.60 \pm 2.09$ & $40.50 \pm 1.33$ & $113.00 \pm 1.67$ & $90.00 \pm 3.12$ \\
Jun. & $60.00 \pm 1.74$ & $31.38 \pm 2.23$ & $75.00 \pm 2.44$ & $50.00 \pm 2.73$ \\
Jul. & $59.00 \pm \pm 2.43$ & $20.00 \pm 1.97$ & $60.00 \pm 3.15$ & $50.00 \pm 2.75$ \\
\hline
\end{tabular}

\section{DISCUSSION}

The present study revealed that at both Suez Canal study sites, mature females and brooding males $H$. fuscus were found each month, indicating that they have a prolonged mating season, although most mature specimens were collected in mid winter-early summer. Female gonado-somatic indices (GSI) showed seasonal changes with a GSI peak that coincided with the peak occurrence of mature ovarian stages in female seahorses. The range of ova development stages found in female ovaries indicated that only a proportion of ova are transferred to males at each mating, and that they may mate many times throughout the reproductive season. This is known as fractional spawning (Vincent, 1990; Foster and Vincent, 2004). Vincent (1990) observed that $H$. fuscus in Australian waters bred continuously either in the wild or in the laboratory, although actual mating has not been observed directly in wild $H$. fuscus. A prolonged breeding season and fractional spawning may have a population replenishment advantage for this species by ensuring a prolonged period of juvenile production during each year if the seahorse populations experience episodic impact events.

Comparison of the reproductive cycle of $H$. fuscus with that of other Hippocampus spp. shows similarities as well as differences; Balasubramanian (2002) reported that $H$. Kelloggi from the Caddalore Coast was a continuous spawner with peak spawning extending from October to February. Perante et al. (2002) found that pregnant $H$. comes occurred year round but with a reproductive peak during the rainy season. In contrast, the spawning season of $H$. capensis is generally during the summer months when water temperature exceeds $20^{\circ} \mathrm{C}$ (Lockyear et al., 1997). All the previous studies indicate that both spawning season and peak of reproduction for Hippocampus sp are flexible and are probably closely linked to environmental conditions. Generally, the duration of breeding season is longer in seahorses in tropical than temperate waters 
with representative breeding durations of 6-12 months for tropical species and 4-8 months for temperate species (Foster \& Vincent, 2004), although there are exceptions to this ( Poortenaar et al., 2004; Woods, 2005). According to Foster and Vincent (2004), seahorse breeding season can be influenced by environmental factors such as photoperiod, temperature, food availability, rainy season and moon phase. peak periods of reproduction for $H$. guttulatus were related to full moon phase in Arcachon Basin, France (Boisseau, 1967), whilst it was related to rainy season for $H$. comes in the Philippines (Perante et al., 2002).

The fecundity of $H$. fuscus showed considerable variation between Great Bitter Lake and Lake Timsah. Although larger female seahorses were observed in, and collected from Lake Timsah, comparison of similar size classes revealed that female $H$. fuscus from Lake Timsah were relatively more fecund. Generally, seahorse fecundity varies according to species, age and changes in environmental conditions (Foster and Vincent, 2004). In the present study, the difference in fecundity between the two lakes could be the result of salinity differences; Great Bitter Lake has a higher salinity (mean $39.6 \pm 1.2 \%$ ) than Lake Timsah (mean $28.8 \pm 3.9 \%$ ). In Great Bitter Lake, female $H$. fuscus may direct more energy to osmoregulation needed for the to the reproductive activity which is considered to be a significant energetic investment for seahorses. $H$. zosterae egg clutches represent from $8 \%$ to $29 \%$ of a female's body weight (Masonjones, 1997). Some seahorse species show high capacity to tolerate a wide range of salinity, such as $H$. erectus which can live in seawater ranging from 9.2 to $35.5 \%$ o (Teixeira and Musick, 2001), but this will influence metabolic expenditure. HilomenGarcia et al. (2003) investigated the salinity tolerance of the euryhaline H. kuda and found that juvenile growth and survival peaked at between 15 and 20\%o, and decreased between 5 and $10 \%$ and between 40 and 50\%o. Alternatively, there may be other environmental or ecological factors that are responsible for differential female fecundity between the two study sites. Great Bitter Lake and Lake Timsah differ in their benthic sediment composition and suspended sediment-loading, heavy metal loadings, tidal regimes and biota (Ghobashy and Komy, 1980; El-Azim and El-Moselhy, 2005; Ali and Gab-Alla, 2007). So differential aspect of reproduction in H. fuscus in the Suez Canal requires further investigation.

In current study, the fecundity is the first published estimates for $H$. fuscus in the wild. As a comparison, the maximum fecundity of the similar-sized $H$. erectus is estimated at 90 to 1313 ova for females of 6 to $12.3 \mathrm{~cm}$ in height (Teixeira and Musick, 2001), which is greater than the maximum recorded fecundity of for $H$. fuscus. Relative female fecundity varies considerably, both on a per brood basis and per breeding season, among different seahorse species, but with a generall increasing female fecundity associated with increasing size (Vincent, 1990; Foster and Vincent, 2004). In comparison with other marine teleosts, seahorse's fecundity is significantly lower, but their maternal investment is higher for each ova due to their significantly larger ova size (Foster and Vincent, 2004).

At the two studied areas of the Suez Canal, female fecundity was positively correlated with seahorse height, total weight, and gonad weight, but these correlations were generally weak. Fecundity-height and fecundity-total weight relationships had a weak correlations that may be due to the fact that they are fractional spawners of the seahorses (Vincent, 1990) that mature, ovulate and spawn only part of their mature ova (clutch) at each mating event. This is in contrast to multiple spawners, which release all mature oocytes and start again with primary oocytes (Wallace and Selman, 1981). Thus, some mature female $H$. fuscus of similar size (height or weight) may have already transferred part of their clutch to males. The weak correlation between fecundity and gonad weight could also be attributed to $H$. fuscus's ovary type (asynchronous type), which possesses a heterogeneous population of follicles at all developmental stages 
(Wallace and Selman, 1981). Thus, two females with the same gonads weight may have different ratios of ova at different maturity stages and, therefore, different total ovary weight.

At both study sites, the diameter of mature ova of $\mathrm{H}$. fuscus was comparatively large, with average diameter $1.7 \pm 0.49 \mathrm{~mm}$ and $1.9 \pm 0.38 \mathrm{~mm}$ in Great Bitter Lake and Lake Timsah respectively. Vincent (1990) estimated a similar ova diameter (1.8mm) for the same species in an ex-situ study. This is consistent with the relatively large ova size of most seahorse species, and is a major factor in seahorses being able to produce relatively large-sized independent juveniles at birth (Foster and Vincent, 2004). Slight differences in ova diameter among different seahorse species is related to female size; egg size may increase with the female size in some species (Vincent and Sadler, 1995).

In the current study, the heights of brooding male $H$. fuscus with the brood number is positively correlated, although the correlations were weak. In contrast, Vincent (1990) found that male size negatively correlated with number of eggs or embryo within pouch in $H$. fuscus reared in captivity. In her ex-situ study, she also explained that larger males with larger pouches mated with proportionally smaller females. Thus, larger male seahorses may not always have a full brood pouch. Generally, the brood size of male seahorses is positively correlated with male size (either height/length or weight), with larger males producing larger broods (Strawn, 1958; Texeira and Musick, 2001; Woods, 2005). This relationship may be explained by brood pouch volume, and hence ova/embryo-carrying capacity, increasing as males increase in overall size. However, it is likely that larger brood sizes in larger male seahorses are the result of these males mating with larger females with greater reproductive output, rather than larger male brood pouch volume directly. There is some evidence that larger male seahorses pair preferentially with larger females (e.g., Vincent and Giles, 2003) and, thus available female size may be the key determinant of the number of young released by the male, not male size or pouch volume.

In the present study, the females $H$. fuscus have fecundity more than males in the sampled populations (i.e., mean number of ripe ova or clutch size exceeded mean brood number). This higher female fecundity in $H$. fuscus is in agreement with observation from ex-situ studies (Vincent, 1990), where part or sometimes the entire clutch are not successfully transferred from female to male seahorses during mating. These results are also consistent with a study on two pipefish, Nerphis ophidion and Syngnathus typhle; where in both species females had higher fecundity than males; $N$. ophidion females could fill 1.8 males pouch capacity during the average course of one incubation period, and S. typhle females could fill 1.9 males pouch capacity during the same period (Berglund et al., 1989).

The nutritional status and condition of female seahorse influences incubation success because embryonic viability probably reflects the chemical composition of the yolk (Nosho, 1981) and maternally-derived components of the marsupial fluid help nourish developing young in the male's brood pouch (Boisseau, 1967). Nevertheless, male seahorses probably also have a large influence on pouch success as they control fertilization, aeration, osmoregulation and non-maternal nutrient provision in the pouch and incur a metabolic cost in doing so. Masonjones (2001) recorded metabolic rate increases of $10-52 \%$ over pre-gravid levels in pregnant male $H$. zosterae. Therefore, it is possible that male seahorses during mating may adjust reproductive investment in relation to available resources by accepting a restricted number of transferred ova (Berglund et al., 1989), or through a reduction strategy within the pouch post-mating (Vincent, 1990). This, ova loss during transfer from females to males during mating, or the re-absorption of non-viable ova within the male's pouch, may explain the relative differences in female and male $H$. fuscus fecundity observed. 
In conclusion, the current study provide the first detailed information on reproductive patterns and fecundity in wild H. fuscus in the Suez Canal. This information is very important to the conservation and management of this exploited, and little studied, seahorse species.

\section{ACKNOWLEDGEMENT}

The aouthors would like to thank Prof. Dr. Salah G. El-Etreby of the Marine Science Dept., Suez Canal University, for his invaluable advice and guidance during the course of this study.

\section{REFERENCES}

Gab-Alla, A. A-F ( 2007). Ecological study on community of exotic invasive seaweed Caulerpa prolifera in Suez Canal and its associated macro invertebrates. J. Appl. Sci., 7(5): 679-686.

Balasubramanian, R. (2002). Studies on seahorses with special reference to Hippocampus kelloggi, Southeast of India. Unpublished Ph.D. thesis, Annamalia University, India.

Baum, J. K. and Vincent, A. C. J. (2005). Magnitude and inferred impacts of the seahorse trade in Latin America. Env. Cons., 32(4): 305-319.

Begovac, P. C.; Wallace, R. A. (1987). Ovary of the pipefish, Syngnathus scove lli. J. Morph. 193:117-133.

Begovac, P. C. and Wallace, R. A. (1988). Stages of oocytes development in the pipefish, Syngnathus scovelli. J. Morph., 197: 353-369.

Berglund, A.; Rosenqvist, G. and Svensson, I. (1989). Reproductive success of females limited by males in two pipefish species. Amer. Nat., 133: 506-516.

Bell, E. M.; Lockyear, J. F.; McPherson, J. M.; Marsden, A. D. and Vincent, A. C. J. (2003). First field studies of an endangered South African seahorse, Hippocampus capensis. Env. Biol. Fish., 67: 35-46.

Boisseau, J. (1967). Les régulations hormonales de l'incubation chez un Vertèbre male: recherches sur la reproduction de l'Hippocampe. $\mathrm{PhD}$ thesis, l'Université de Bordeaux, France.

El-Azim, H. A. and El-Moselhy, Kh. M. (2005). Determination and partitioning of metals in sediments along the Suez Canal by sequential extraction. J. Mar. Syst., 56: 363-374.

Foster, S. J. and Vincent, A. C. J. (2004). Life history and ecology of seahorses: implications for conservation and management. J. Fish Biol., 65: 1-61.

Ghobashy, A. F. A. and El Komy, M. M. (1980). Fouling in Lake Timsah. Aquat. Ecol., 14(3): 179-185.

Golani, D. and Fine, M. (2002). On the occurrence of Hippocampus fuscus in the eastern Mediterranean. J. Fish Biol., 60:764-766.

Hilomen-Garcia, G. V.; Delos Reyes, R. and Garcia, C. M. H. (2003). Tolerance of seahorse Hippocampus kuda (Bleeker) juveniles to various salinities. J. Appl. Ichth., 19: 94-98.

Kuiter, R. H. (2003). Seahorses, Pipefishes and their relatives. A comprehensive guide to the Syngnathiformes. TMC Publishing, Chorleywood, U.K. 237pp.

Lockyear, J.; Kaiser, H. and Hecht, T. (1997). Studies on the captive breeding of the Knysna seahorse, Hippocampus capensis. Aquar. Sci. Cons., 1: 129-136.

Lourie S. A.; Vincent A.C. J. and Hall H. J. (1999). Seahorses: an identification guide to the world's species and their conservation. Project Seahorse, London, UK. $211 \mathrm{pp}$. 
Lourie, S. A.; Foster, S. J.; Cooper, E. W. and Vincent, A. C. J. (2004). A guide to the identification of seahorses. Project Seahorse and TRAFFIC North America, Washington, D.C., University of British Columbia and World Wildlife Fund. $114 \mathrm{pp}$.

Martin-Smith, K. M. and Vincent, A. C. J. (2005). Seahorse declines in the Derwent estuary, Tasmania in the absence of fishing pressure. Biol. Cons., 123: 533-545.

Martin-Smith, K. M. and Vincent, A. C. J. (2006). Exploitation and trade of Australian seahorses, pipehorses, sea dragons and pipefishes (Family Syngnathidae). Oryx 40(2): 141-151.

Masonjones, H. D. (2001). The effect of social context and reproductive status on the metabolic rate of dwarf seahorses (Hippocampus zosterae). Comp. Bioch. Phys., 129(A): 541-555.

Nosho, T. (1981). Salmonid broodstock management . proceedings of workshop held in Seatel, Washington May 1981 and March 1981 Washington Sea grant.

Perante, N. C.; Pajaro, M. G.; Meeuwig, J. J. and Vincent, A. C. J. ( 2002). Biology of a seahorse species, Hippocampus comes in the central Philippines. J. Fish Biol., 60: 821-837.

Poortenaar, C. W.; Woods, C. M. C.; James, P. J.; Giambartolomei, F. M. and Lokman, P. M. (2004). Reproductive biology of female big-bellied seahorses. J. Fish Biol., 64: 717-725.

Project Seahorse (2003). Hippocampus fuscus. In: IUCN 2007. 2007 IUCN Red List of Threatened Species. < www.iucnredlist.org > . Downloaded on 18 March 2008.

Salin, K. R.; Yohannan, T. M. and Mohanakumaran Nair, C. (2005). Fisheries and trade of seahorses, Hippocampus spp., in southern India. Fish. Man. Ecol. 12:269-273.

Selman, K.; Wallace, R. A. and Player, D. (1991). Ovary of the seahorse, Hippocampus erectus. J. Morph., 209: 285-304.

Strawn, K. (1958).Life history of the pigmy seahorse, Hippocampus zosterae Jordan and Gilbert, at Cedar Key, Florida. Copeia 1958: 16-22.

Texeira, R. L. and Musick, J. A. (2001). Reproduction and food habits of the lined seahorse, Hippocampus erectus (Teleostei: Syngnathidae) of Chespeake Bay, Virginia. Rev. Bras. Biol., 61: 79-90.

Vincent, A. C. J. (1990). Reproductive ecology of seahorses. Unpublished PhD thesis. University of Cambridge, $107 \mathrm{pp}$.

Vincent A. C. J. (1996). The international trade in seahorses. TRAFFIC International, Cambridge, United Kingdom, 163pp.

Vincent, A. C. J. and Sadler, L. M. (1995). Faithful pair bonds in wild seahorses, Hippocampus whitei. Anim. Behav., 50:1557-1569.

Vincent, A. C. J. and Giles, B. (2003). Correlates of reproductive success in a wild population of Hippocampus whitei. J. Fish Biol., 63: 344-355.

Wallace, R. A. and Selman, K. (1981). Cellular and dynamic aspects of oocytes growth in teleosts. Amer. Zool., 21: 325-343.

Woods, C. M. C. (2005). Reproductive output of male seahorses, Hippocampus abdominalis, from Wellington Harbour, New Zealand: implications for conservation. N.Z. J. Mar. Fres. Res., 39(4): 881-888. 


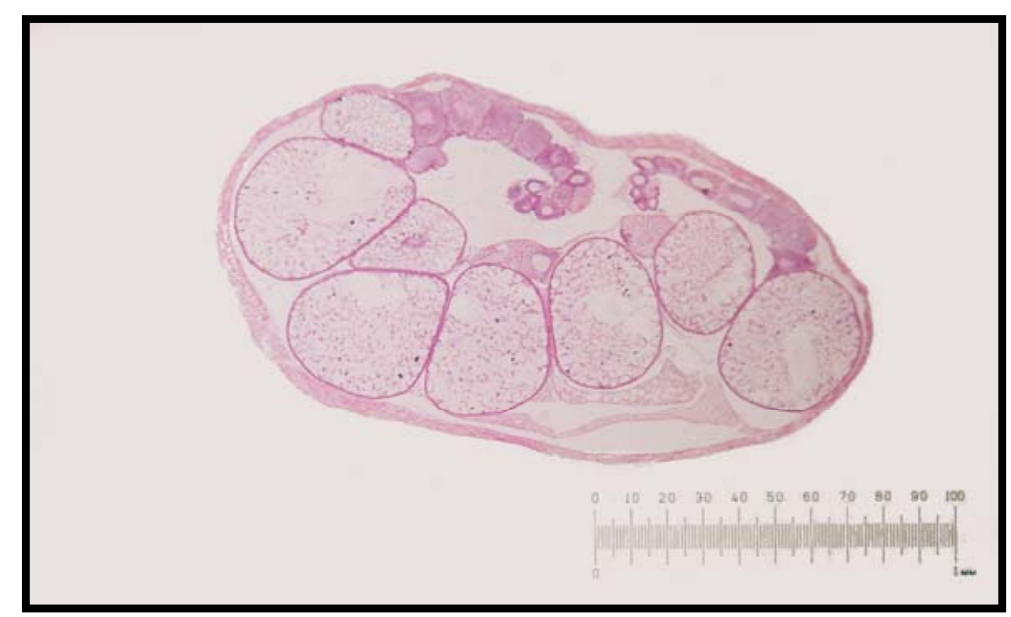

Fig. 2: A cross-section through an ovary of a female Hippocampus fuscus in the previtellogenic stage (I). CA: cortical alveoli oocytes;GR:germinal ridges; LE: luminal epithelium; MW: muscular wall; and; PN: perinucleolus oocytes.

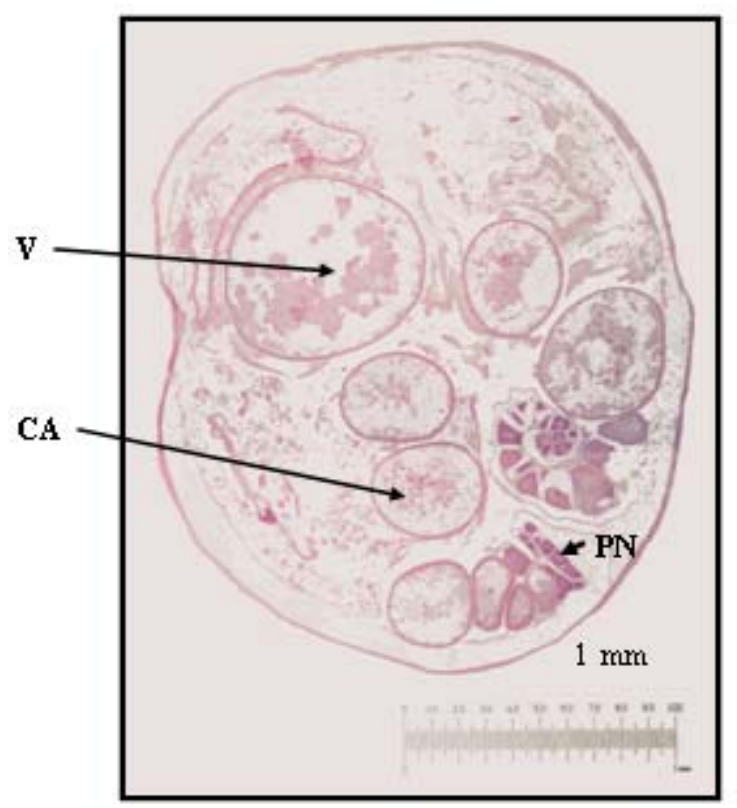

Fig. 3: A cross-section of the ovary of a female Hippocampus fuscus in the vitellogenic stage (II). PN: perinucleolus oocyte; CA: Cortical alveoli oocyte; V: Vitellogenic oocyte.

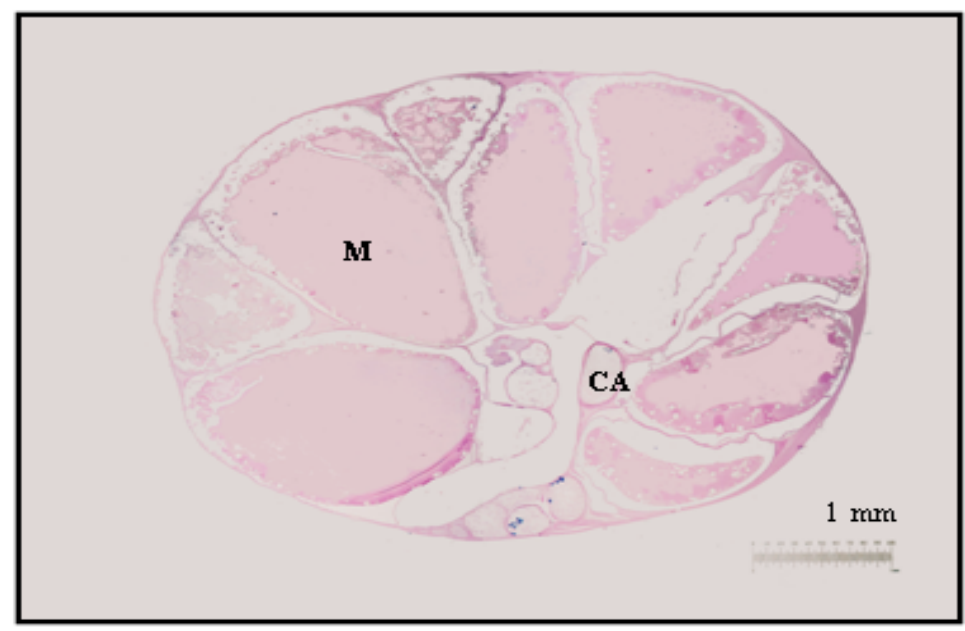


Fig. 4: Cross-section of the ovary of a female Hippocampus fuscus in the mature stage (III). CA, Cortical alveoli oocyte; M, mature oocytes.

\section{ARABIC SUMMARY}

بيولوجية التكاثر لحصان البحر هييوكمباس فيوسكاس (تليوسني: سيجناثيدي)، في قناة السويس، مصر

$$
\begin{aligned}
& \text { أشرف ابراهيم أحمد و هويدا رشدي جبر و علا خواسك } \\
& \text { قسم علوم البحار ـ كلية العلوم- جامعة قناة السويس عليس }
\end{aligned}
$$

في هذا البحث تم دراسة بيولوجية التكاثر لحصان البحر هيبوكمباس فيوسكاس في كل من البحير ات التئس المرة

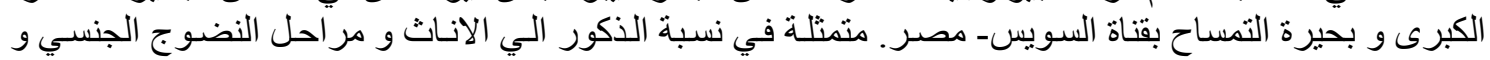

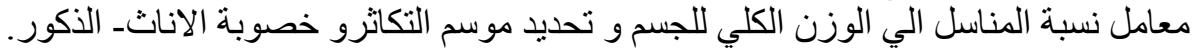

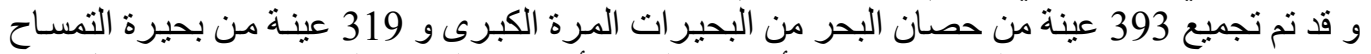

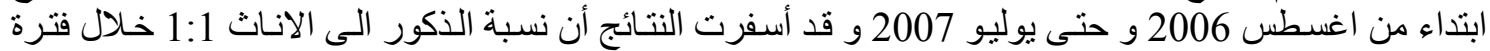

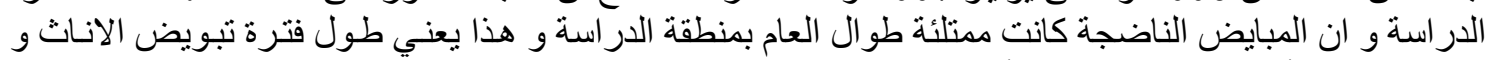

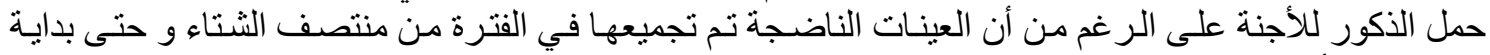

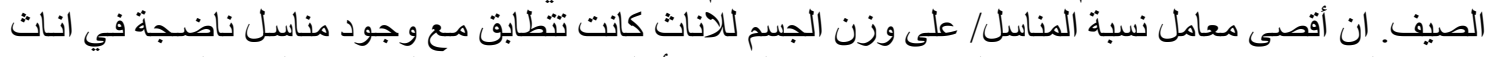

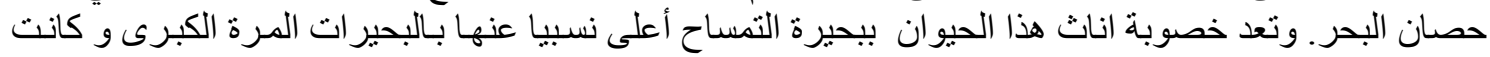

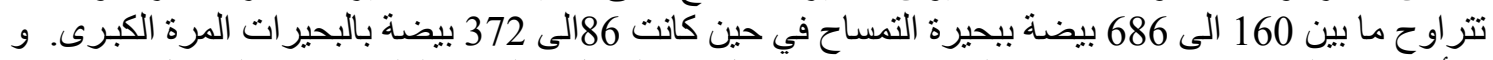

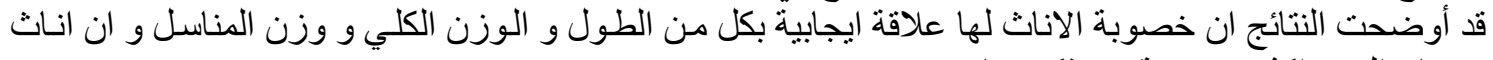
حصان البحر اكثر خصوبة من ذان ذكور هان.

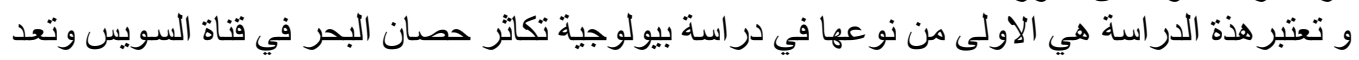

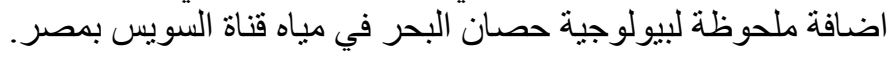

